EVS26

Los Angeles, California, May 6-9, 2012

\title{
Evaluation of battery requirements for hybrid and electric city buses
}

\author{
Antti Lajunen \\ Aalto University, School of Engineering, Puumiehenkuja 5a,00076 Aalto, Finland, antti.lajunen@aalto.fi
}

\begin{abstract}
This paper presents an evaluation of battery requirements for hybrid and electric city buses. Technical specifications of recently developed lithium based batteries and vehicle simulation results are used as basis for the evaluation. The battery requirements are evaluated in terms of power and energy capacity, calendar and cycle life as well as costs. Conventional diesel, parallel and series hybrid, plug-in hybrid, and electric city bus were chosen as different bus applications. The simulation results of the diesel powered city bus were used as reference for performance requirement and a point of comparison in operation cost analysis. Simulations were carried out in four different types of driving cycles. The evaluation shows that lithium based batteries offer sufficient specific power and energy capacity meanwhile requirements for costs and cycle life durability are dependent on the bus application, the driving cycle, and the operation schedule. Especially a power intensive driving cycle can be challenging for the high energy batteries in terms of cycle life. There are also noticeable differences in performance between different battery chemistries. For plug-in hybrid and electric city buses, fast recharge capability can increase significantly the costeffectiveness in bus fleet operation. The operation cost analysis also indicates that the battery cost is more important for the plug-in hybrid and electric buses whereas the initial cost of the bus is a major factor for the charge sustaining parallel and series hybrid buses.
\end{abstract}

Keywords: battery requirements, hybrid bus, electric bus, city bus, lithium-ion battery, cost analysis

\section{Introduction}

For hybrid and electric city buses, the energy storage is one of the most important components in terms of overall energy efficiency, bus lifecycle and costs [1]. During the recent years, lithium based batteries have proven to be suitable choice for hybrid and electric passenger vehicles. They offer sufficient power and energy capacity, they are relatively safe, and their calendar and cycle life is long enough at least for hybrid vehicles [2], [3]. However, there are still some doubts about safety, durability and reliability [4], [5]. The lifetime of a battery can be drastically shortened under high temperatures, high currents and high energy throughput. Battery aging and lifecycle has been under growing interest in several research studies e.g. [6], [7]. Lithium based batteries are still quite costly for vehicular applications but numerous presented estimations predict that, with high volume production, the costs can be significantly reduced as it is shown in [8]. 
In hybrid and electric city buses, the most typical choice is to use batteries as sole energy storage. During the last decade, research has been made with rising activity to define requirements for batteries, particularly in vehicular applications [5], [9]. There is also a growing interest for improving performance characteristics of batteries to make them more suitable for hybrid and electric vehicles [10], [11].

This paper evaluates battery requirements for parallel (PAR) and series (SER) hybrid, plug-in hybrid (PHV), and electric (EV) city buses. The research work was carried out by different simulation studies and a comprehensive analysis of the simulation results. In addition, the energy efficiency of the different bus applications was analysed and the battery impact on the cost effectiveness in bus fleet operation was evaluated.

\section{Evaluation parameters}

Required technical performance of the battery is based on the needed power and energy in a typical driving cycle of a city bus. The power and energy capacity of the battery was evaluated then in relation to the performance of the individual bus application. USABC (U.S. Advanced Battery Consortium) defined battery lifecycle targets are used as reference for lifecycle evaluations. Even if those requirements are designed for passenger vehicles, it is assumed here that similar requirements would be applicable also for heavy hybrid and electric vehicle applications.

As typical operation pattern of a city bus is energy intensive, cycle life requirement can be quite high for lithium based batteries which leads to the need of replacing the battery pack many times during the lifetime of a bus. Because a shallow discharge-charge cycle is relatively difficult to define accurately for different types of batteries, the battery cycle life is determined based on the lifetime energy throughput. USABC defined 5000 deep cycles were used as a reference for this energy.

For cost estimations, currently commercially available lithium based batteries are used as reference but also predictions of future costs are taken into account [8]. Table 1 presents the different parameters for cost and payback calculation. The cost values and factors are mainly based on the findings of a recent study of optimization and allocation of a bus fleet [12]. Battery second life costs or opportunities are not considered in this research.
The payback time for the higher costs (including battery pack replacements) of the hybrid and electric city bus was defined for three different battery cost scenarios: 1) $1050 €(\sim 1400 \$), 2) 600 €$ $(\sim 800 \$)$ and 3) $150 €(\sim 200 \$)$ per kilowatt-hour.

Table 1: Cost calculation parameters.

\begin{tabular}{|l|c|c|}
\hline Definition & Variable & Value \\
\hline $\begin{array}{l}\text { Conventional city bus } \\
\text { initial cost }(€)\end{array}$ & $\mathrm{C}_{\mathrm{CONV}}$ & 250000 \\
\hline $\begin{array}{l}\text { Hybrid and electric city } \\
\text { bus initial cost factor } \\
\text { (without battery cost) }\end{array}$ & $\mathrm{f}_{\mathrm{ELEC}}$ & 1.2 \\
\hline Diesel price $(€ / \mathrm{l})$ & $\mathrm{C}_{\mathrm{D}}$ & 1.43 \\
\hline Electricity price $(€ / \mathrm{kWh})$ & $\mathrm{C}_{\mathrm{E}}$ & 0.12 \\
\hline $\begin{array}{l}\text { Maintenance cost for } \\
\text { diesel city bus }(€ / \mathrm{km})\end{array}$ & $\mathrm{C}_{\mathrm{M}}$ & 0.26 \\
\hline
\end{tabular}

Equation 1 was used to define the needed kilometers in operation for amortizing the higher costs.

$$
D_{k m}=\frac{N_{B A T T} C_{B A T T}+C_{C O N V}\left(f_{E L E C}-1\right)}{C_{o p_{-} C O N V}-C_{o p_{-} E L E C}}
$$

where $N_{B A T T}$ is the number of battery pack replacements, $C_{B A T T}$ is the battery initial cost, and $C_{\text {op_CONV }}$ and $C_{\text {Op_ELEC }}$ are the operation costs per kilometer for conventional (CONV), and hybrid or electric (ELEC) city bus, respectively. In this evaluation, the operation costs are based on the diesel and electricity consumption, and maintenance costs. The maintenance costs include general repairs and spare parts (also tires) [12]. Compared to the diesel city bus, the maintenance costs were assumed to be $15 \%$ lower for parallel hybrid, $20 \%$ lower for series hybrid, $25 \%$ lower for plug-in hybrid, and 30\% lower for electric city bus. This assumption is based on the knowledge that with electric drive, there is less frequent need for maintenance and with electric bus there is no engine to be maintained.

The number of battery packs replacements was calculated with Equation 2.

$$
N_{B A T T}=\frac{C_{B A T T}+C_{C O N V}\left(f_{E L E C}-1\right)}{\frac{E_{T O T}}{E_{K M}}\left(C_{o p_{-} C O N V}-C_{o p_{-} E L E C}\right)-C_{B A T T}}
$$

where $E_{T O T}$ is the total lifetime energy throughput for battery pack and $E_{K M}$ is the battery energy throughput per kilometer. For equally comparing different bus applications, and the impact of the battery, the bus operational cost and payback time 
analysis was conducted for a bus fleet. For each driving cycle, a minimum amount of buses was defined with Equation 3 for conventional and charge sustaining hybrid buses.

$$
N_{B C}=\frac{t_{R}}{t_{D}}
$$

where $t_{R}$ is the bus route duration time and $t_{D}$ is the time between buses in operation. A bus route consists of one or more driving cycles. For plugin hybrid bus, the minimum amount of buses was defined to be $N_{B C}+1$, because there is no operational limit and fast recharge at the bus stop was not considered. For plug-in hybrid bus, the required operation range in cycles before recharging the batteries was defined by Equation 4.

$$
R_{O}=\frac{t_{C H G} N_{C} N_{B C}}{t_{R}}
$$

where $t_{C H G}$ is the charging time of a bus and $N_{C}$ is the number of driving cycles in a route. For plug-in hybrid and electric bus, the charging time of the bus was taken into account by Equation 5 .

$$
N_{B E}=N_{B C}\left(1+\frac{t_{C H G}}{R_{O} t_{C}}\right)
$$

where $t_{C}$ is the driving cycle time and $R_{O}$ is the operation range in cycles. It was assumed that buses are not recharged at the same time.

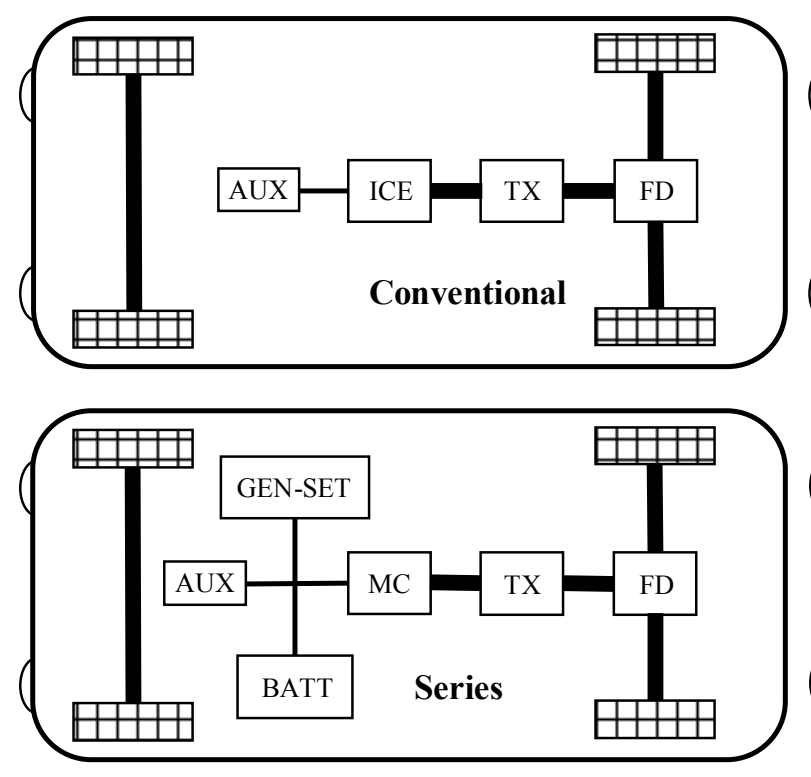

\section{Simulation models}

\subsection{General information}

The common technical characteristics (Table 2) of the simulation models are based on a lightweight, diesel engine (maximum power $202 \mathrm{~kW}$ ) powered city bus with a 5 gear automatic transmission. The configuration of the main components of the hybrid and electric bus models was done in respect of the requirements of the chosen driving cycles. The hybrid and electric bus models have at least the same performance as the reference diesel bus model.

Table 2: Technical characteristics

\begin{tabular}{|l|c|}
\hline Parameter & Value \\
\hline Curb weight $(\mathrm{kg})$ & 8500 \\
\hline Vehicle frontal area $\left(\mathrm{m}^{2}\right)$ & 6.2 \\
\hline Drag coefficient & 0.6 \\
\hline Rolling resistance & 0.01 \\
\hline Wheelbase $(\mathrm{m})$ & 6.5 \\
\hline Front weight fraction & 0.34 \\
\hline Centre of gravity, height $(\mathrm{m})$ & 1.0 \\
\hline
\end{tabular}

A schematic layout of the different city bus simulation models is presented in Fig. 1. The technical information for the mechanical driveline, from engine to wheels, was already acquired in earlier research [13]. The baseline engine had been measured in a laboratory test facility which allowed for creating a realistic steady state engine and emission maps.

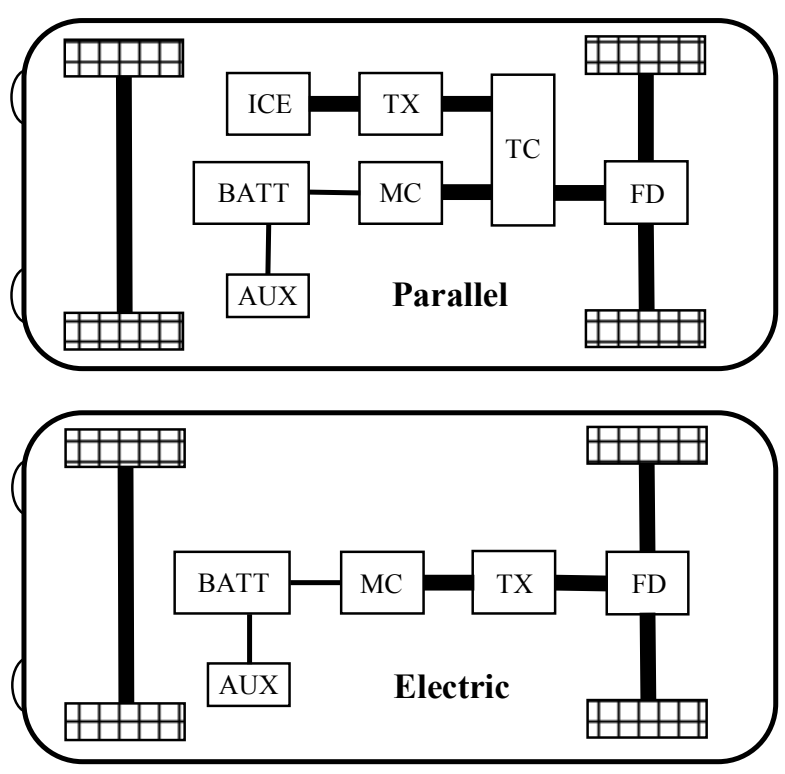

Figure 1: Schematic and simplified layout of the different city bus simulation models (ICE $=$ diesel engine, $\mathrm{TX}=$ transmission, $\mathrm{FD}=$ final drive, $\mathrm{AUX}=$ auxiliaries, $\mathrm{TC}=$ torque coupler, $\mathrm{MC}=$ motor/controller, $\mathrm{BATT}=$ battery, GEN-SET = engine-generator). 
The downsized engine versions for hybrid bus models were calculated from this baseline engine by using Willans approximation method. The electric motor and generator models were configured with measured efficiency maps. The simulation models can also operate with multiple battery packs which takes place in the case of plug-in hybrid and electric buses.

Dimensioning of the main components (engine, electric motor, transmission and battery) was done the way that all the bus models have equal performance in terms of acceleration capability, maximum speed and passenger capacity on the chosen driving cycles.

\subsection{Simulation environment}

ADVISOR vehicle simulation program was used as the simulation environment. The program is designed for rapid analysis of the performance and fuel economy of conventional and advanced, light and heavy-duty vehicle models as well as hybrid electric and fuel cell vehicle models [14]. In this research, the development of the simulation models was mostly concentrated in the energy management strategy, configuration of the main component data and battery model development.

\subsection{Battery modeling}

The battery model is based on the model developed for ADVISOR [14]. The original internal resistance model was further modified to correspond to the structure of the lithium ion batteries used in this research. Two battery chemistries were used: lithium polymer (Kokam) and lithium titanate (Altairnano). The battery model was parameterized according to the data provided by the manufacturer. Kokam battery module was measured in laboratory conditions for generating verification data for the battery model. The simulated battery performance corresponded relatively well to the measured performance. The assembly of the Kokam cells and module frame is shown in Fig. 2.

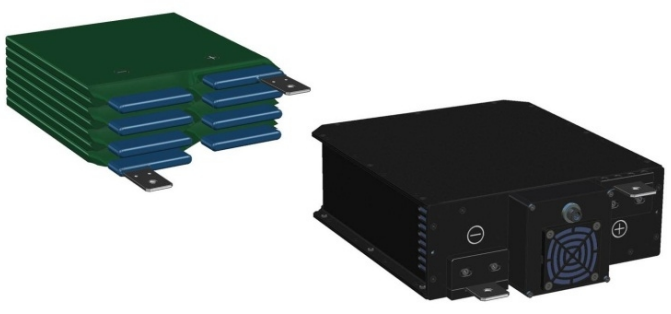

Figure 2: Kokam battery module assembly.
Based on the Kokam module construction, a thermal model was developed for the battery. Thermal parameters of the module were defined based on the measured temperature in different loading conditions. The battery model has an air cooling system.

\subsection{Energy management strategy}

Charge sustaining (CS) energy management strategies were developed for the parallel and series hybrid bus simulation models. The focus was on the development of robust and adaptive rule-based strategies which could be used in different bus driving cycles and in different operation conditions. An optimization study based on dynamic programming was carried out for parameterizing the control strategies. The operation of the engine was optimized in respect of energy consumption by calculating the best operation mode based on the efficiencies of the main components and battery state of charge (SOC). Fig. 3 and 4 illustrate the operation of the control strategies of charge sustaining parallel and series hybrid by describing the operating mode control as function of required driving power and SOC.

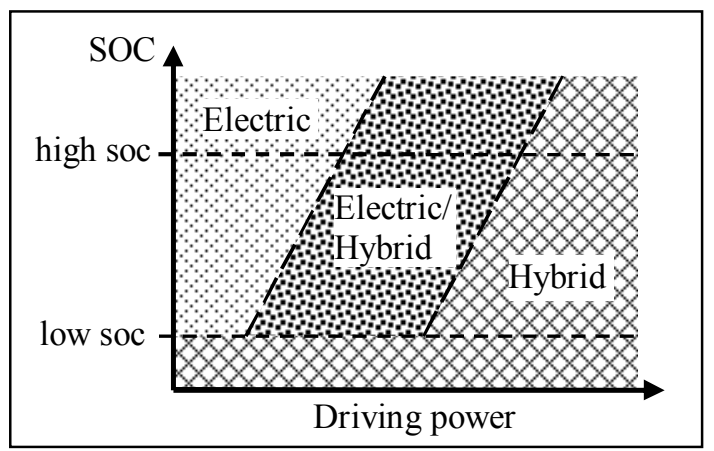

Figure 3: Parallel hybrid operation.

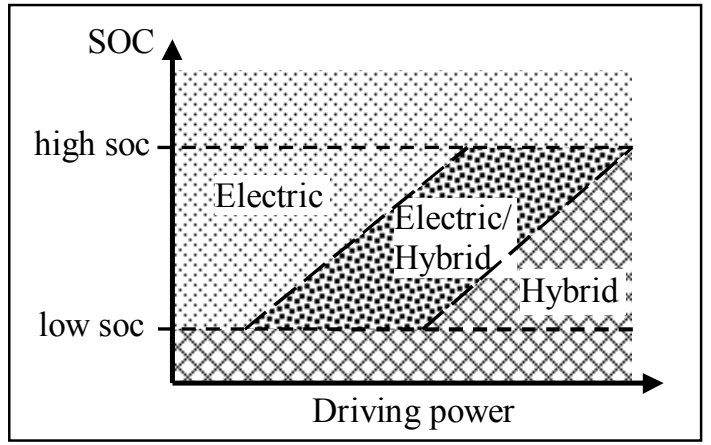

Figure 4: Series hybrid operation.

The SOC levels "low soc" and "high soc" correspond to predefined state of charge levels for battery system. 
Table 3: Characteristics of the driving cycles used in simulations.

\begin{tabular}{|l|c|c|c|c|}
\hline Cycle & $\mathbf{5 5 0}$ & BR & OCC & NYC \\
\hline Max speed $(\mathrm{km} / \mathrm{h})$ & 83.3 & 58.2 & 65.4 & 49.6 \\
\hline Average total speed $(\mathrm{km} / \mathrm{h})$ & 31.5 & 22.5 & 19.8 & 5.9 \\
\hline Average speed $(\mathrm{km} / \mathrm{h})$ & 35.9 & 30.1 & 25.2 & 18.1 \\
\hline Distance $(\mathrm{km})$ & 28.6 & 10.9 & 10.5 & 1.0 \\
\hline Stop time percentage & $13.3 \%$ & $25.7 \%$ & $20.7 \%$ & $61.5 \%$ \\
\hline Stops per km & 1.4 & 2.6 & 2.9 & 10.1 \\
\hline Max acceleration $\left(\mathrm{m} / \mathrm{s}^{2}\right)$ & 1.8 & 2.4 & 1.8 & 2.8 \\
\hline Min acceleration $\left(\mathrm{m} / \mathrm{s}^{2}\right)$ & -2.1 & -3.6 & -2.3 & -2.1 \\
\hline
\end{tabular}

For charge sustaining strategies, these SOC limits were around $60 \%$ and for the plug-in hybrid and electric bus, the lower limit of SOC was $20 \%$ and the depth of discharge (DOD) $70 \%$. In the plug-in hybrid bus operation, the battery was first depleted to its lower limit of SOC and then operated in hybrid mode.

\section{Configuration of simulations}

\subsection{Simulation cycles and conditions}

As there can be significant variations in performance requirements depending on the driving cycle, four different city bus driving cycles were chosen for simulations. Table 3 presents characteristics of these cycles, which are Braunschweig (BR), route 550 (a Helsinki region bus line), Orange County Bus Cycle (OCC) and New York Bus (NYC). The route 550 is especially interesting having some sub urban nature which differs in demands of top speed and stops per driven distance compared to traditional reference cycles.

Constant auxiliary power of $5 \mathrm{~kW}$ was used for all bus applications. The bus total weight in simulations consisted of curb weight of $8500 \mathrm{~kg}$, about 20 passengers $(1500 \mathrm{~kg})$ and the weight of the battery $\operatorname{pack}(\mathrm{s})$. All simulations were conducted in $20^{\circ} \mathrm{C}$ of ambient temperature. The battery temperature was kept in between $20-25^{\circ} \mathrm{C}$ with the aid of active cooling.

\subsection{Fleet operation}

The amount of cycles repeated in simulations was based on the fleet operation calculations. The required operation range of the plug-in hybrid was defined by Equation 4. The electric bus model was simulated as many cycles as possible with the battery capacity. In fleet operation calculations, the time between buses in operation $\left(t_{D}\right)$ was defined to be 15 minutes all other cycles than NYC. For NYC, it was decided to be 5 minutes due to the city center type of the cycle. The battery external recharge current was $2 \mathrm{C}$ as C-rate. The current was limited by total recharge power of $200 \mathrm{~kW}$.

\subsection{Component configuration}

Different configuration options were defined for the battery pack. These options were generated from Kokam 40Ah and Altairnano 60Ah cells. Kokam module has seven cells with nominal voltage of $25.9 \mathrm{~V}$ (Fig. 2) and Altairnano module has 10 cells with nominal voltage of $23 \mathrm{~V}$. Table 4 summarizes the cell characteristics of the two battery types.

Table 4: Battery cell characteristics.

\begin{tabular}{|l|c|c|}
\hline Cell specifications & Kokam & Altairnano \\
\hline Capacity (Ah) & 40 & 60 \\
\hline Cell voltage (V) & 3.7 & 2.3 \\
\hline $\begin{array}{l}\text { Cont. max / Peak } \\
\text { discharge current (A) }\end{array}$ & $320 / 480$ & $360 / 600$ \\
\hline $\begin{array}{l}\text { Cont. max / Peak } \\
\text { charge current (A) }\end{array}$ & $120 / 120$ & $360 / 600$ \\
\hline Weight (kg) & 1.1 & 1.8 \\
\hline Volume (l) & 0.5 & 0.9 \\
\hline $\begin{array}{l}\text { Weight factor* } \\
\text { (cell to pack) }\end{array}$ & 1.4 & 1.6 \\
\hline $\begin{array}{l}\text { Volume factor* } \\
\text { (cell to pack) }\end{array}$ & 2.9 & 2.2 \\
\hline
\end{tabular}

* calculated from actual dimensions

The presented weight and volume factors in Table 4 are based on the actual module and pack dimensions with an air cooling system. Table 5 presents detailed technical information of each generated battery pack configuration. Table 6 describes the configurations of the different bus models. The bus options PAR_1 and PAR_2, and SER_1 and SER_2, operate with charge sustaining control strategy. The plug-in hybrid options (PHV_1 and PHV_2) have small engine-generator $(63 \mathrm{~kW})$ as a range-extender. 
Table 5: Kokam and Altairnano battery pack configuration data

\begin{tabular}{|l|c|c|c|c|c|c|}
\hline Specifications & K40_1 & K40_2 & K40_3 & A50_1 & A50_2 & A50_3 \\
\hline Modules & 12 & 16 & 24 & 12 & 16 & 18 \\
\hline Voltage (V) & 311 & 414 & 622 & 276 & 368 & 414 \\
\hline Weight $(\mathrm{kg})$ & 126 & 168 & 252 & 343 & 458 & 515 \\
\hline Volume $(\mathrm{l})$ & 124 & 165 & 247 & 220 & 293 & 329 \\
\hline Cont. max discharge power $(\mathrm{kW})$ & 99 & 133 & 199 & 99 & 132 & 149 \\
\hline Cont. max charge power $(\mathrm{kW})$ & 37 & 50 & 75 & 99 & 132 & 149 \\
\hline Energy $(\mathrm{kWh})$ & 12.4 & 16.6 & 24.9 & 16.6 & 22.1 & 24.8 \\
\hline
\end{tabular}

Table 6: Configuration of hybrid and electric bus simulation models

\begin{tabular}{|c|c|c|c|c|c|c|c|}
\hline \multirow[b]{2}{*}{ Config } & \multirow[b]{2}{*}{$\begin{array}{c}\text { Engine } \\
\text { power } \\
\max \\
(\mathbf{k W})\end{array}$} & \multirow{2}{*}{$\begin{array}{c}\text { Electric } \\
\text { motor } \\
\text { rated } \\
\text { power } \\
(\mathrm{kW}) \\
\end{array}$} & \multicolumn{5}{|c|}{ Battery pack system configuration } \\
\hline & & & $\begin{array}{c}\text { Battery } \\
\text { configuration }\end{array}$ & $\begin{array}{c}\text { Cont. max } \\
\text { discharge } \\
\text { power }(\mathbf{k W})\end{array}$ & $\begin{array}{c}\text { Cont. max } \\
\text { charge } \\
\text { power }(k W)\end{array}$ & $\begin{array}{c}\text { Total } \\
\text { weight } \\
(\mathrm{kg})\end{array}$ & $\begin{array}{l}\text { Total } \\
\text { energy } \\
(\mathbf{k W h})\end{array}$ \\
\hline PAR 1 & 140 & 100 & $1 \mathrm{~s} 1 \mathrm{p}(\mathrm{K} 401)$ & 99 & 37 & 126 & 12.4 \\
\hline PAR 2 & 140 & 100 & $1 \mathrm{~s} 1 \mathrm{p}\left(\mathrm{A} 60 \_1\right)$ & 99 & 99 & 343 & 16.6 \\
\hline SER_ 1 & 110 & 134 & $1 \mathrm{~s} 1 \mathrm{p}(\mathrm{K} 402)$ & 133 & 50 & 168 & 16.6 \\
\hline SER_2 & 110 & 134 & $1 \mathrm{~s} 1 \mathrm{p}\left(\mathrm{A} 60 \_2\right)$ & 132 & 132 & 458 & 22.1 \\
\hline PHV 1 & 63 & 134 & $1 \mathrm{~s} 2 \mathrm{p}(\mathrm{K} 403)$ & 311 & 149 & 505 & 49.7 \\
\hline PHV 2 & 63 & 134 & $1 \mathrm{~s} 2 \mathrm{p}(\mathrm{A} 603)$ & 207 & 207 & 1030 & 49.7 \\
\hline EV_1 & -- & 134 & $1 \mathrm{~s} 4 \mathrm{p}\left(\mathrm{K} 40 \_3\right)$ & 311 & 298 & 1009 & 99.5 \\
\hline EV_2 & -- & 134 & $1 \mathrm{~s} 4 \mathrm{p}\left(\mathrm{A} 60 \_3\right)$ & 207 & 207 & 2060 & 99.4 \\
\hline
\end{tabular}

The maximum power values for battery pack system, in Table 6, are limited by the maximum current limit of the power electronics and nominal voltage of the battery. The maximum current limit was defined to be 500A.

The battery pack options for the charge sustaining hybrid models were dimensioned the way that they provide similar performance, and they fulfil the minimum performance requirement for the bus. For plug-in hybrid and electric bus, the amount of battery packs is based on equal amount of energy. In the simulations of New York Bus cycle, the battery capacity of plug-in and electric buses was reduced to half of the capacity defined in Table 6 . This was done for having better comparison between the different bus applications. As the New York Bus cycle is relatively short distance and low speed cycle, it is reasonable to have lower capacity energy storage.

\section{Simulation results}

\subsection{Summary}

The simulation results clearly show that the energy efficiency of the city bus can be significantly improved by hybridization and electrification. The improvement depends on the bus application, the driving cycle and also on the battery performance. Fig. 5 presents a summary of the simulation results in terms of energy efficiency increase in reference to the conventional diesel bus.

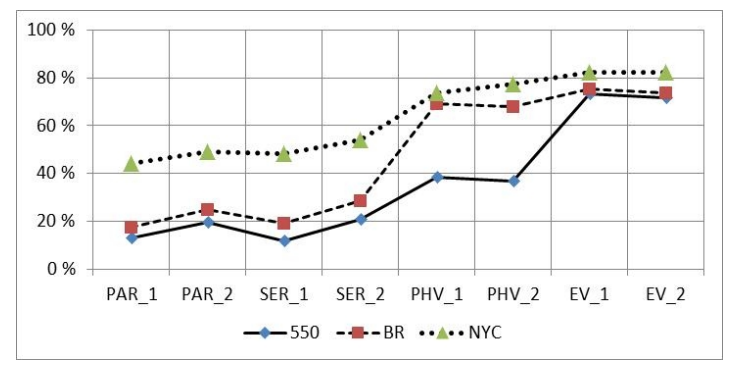

Figure 5: Energy efficiency increase.

The results of the OCC are intentionally left out because they are very similar to the results of the Braunschweig cycle. The energy efficiency results of the plug-in hybrid bus (PHV_1 and 2) should be interpreted carefully because these results are based on the fleet operation where the required operation range has influence on the resulting energy efficiency.

Fig. 6 shows the energy throughput of the battery packs. A general trend can be observed; higher energy and power capacity likely results in an increased energy throughput. The energy 
throughput of the parallel hybrid bus in New York Bus cycle is lot less than the same of the other bus applications. This is because of the limited electric operation range due to the relatively small (less powerful) battery pack and smaller electric motor than the other bus applications.

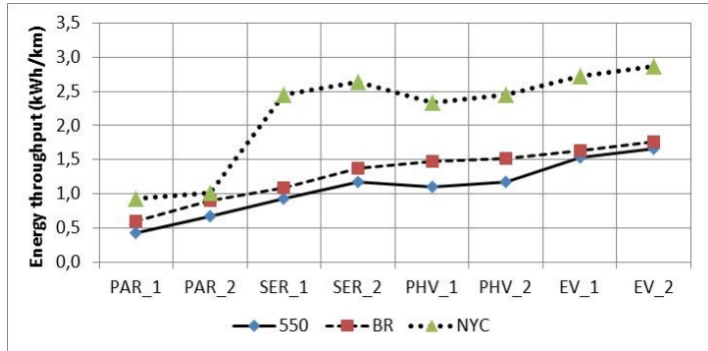

Figure 6: Battery energy throughput.

\subsection{Power and energy capacity}

For charge sustaining hybrid buses, the power capacity of the battery is an important factor. As shown in Fig. 7, the power capacity impacts on the possibility to operate purely on electric mode. The electric operation is presented here as a percentage of the total duration of the driving cycle.

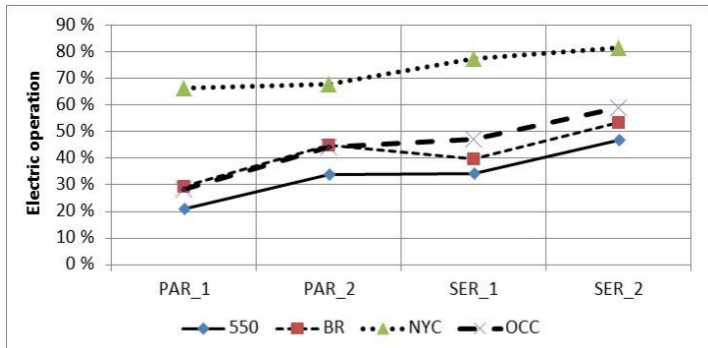

Figure 7: Electric operation of charge sustaining hybrid buses.

As series hybrid has more powerful battery pack than parallel hybrid and full electric drivetrain, it can operate more time on electric mode. The higher charging power capability (cases PAR_2 and SER_2) increases significantly the electric operation time. It also increases braking energy recovery (BER) efficiency which is presented in Fig. 8. The BER efficiency has been calculated as the ratio of recovered braking energy stored in the battery and the total required driving energy at the wheel. Plug-in hybrid and electric buses have automatically high power capacity due to the high amount of energy capacity. Therefore, the BER efficiency is about the same for all of them and it is practically only dependent on the driving cycle.

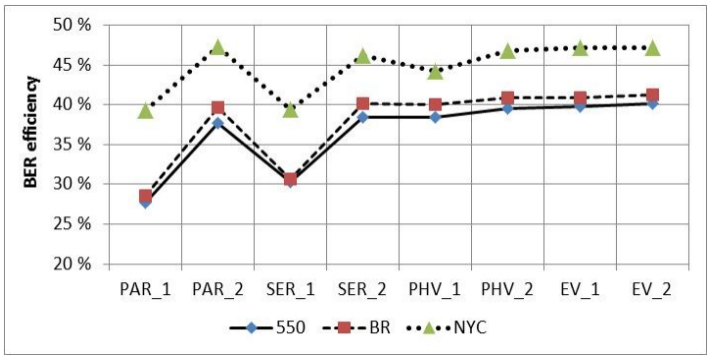

Figure 8: Braking energy recovery efficiency.

\subsection{Battery efficiency}

Fig. 9 presents the round-trip efficiency of the battery pack(s). There is a noticeable advantage in favor for the other battery type (Altairnano) in cases PAR_2 and SER_2. This advantage comes from the lower internal resistance which is basically one of the main reasons for better energy efficiency of these bus options.

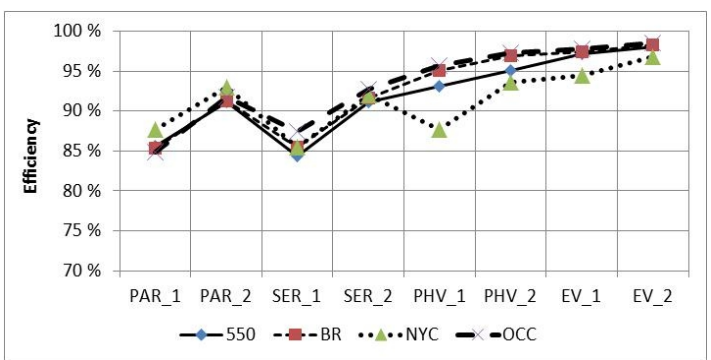

Figure 9: Battery pack round-trip efficiency.

However, the higher weight of the Altairnano battery pack eliminates the efficiency advantage in plug-in hybrid and electric bus operation. In New York Bus cycle, the reduced amount of battery capacity of the plug-in hybrid bus causes a drop of efficiency in the case PHV_1.

\subsection{Lifecycle}

Due to the recharging requirement of plug-in hybrid and electric city buses, the results of the lifecycle and cost are calculated based on a fleet operation of the buses. The minimum amount of buses for each route was determined by Equations 3 and 5.

Typical city bus operation is very energy intensive which leads to high requirements for battery lifecycle. Fig. 10 shows one battery pack life in kilometers for each hybrid and electric bus model. With charge sustaining hybrids, the battery life is relatively low and there are significant differences between the bus applications. 


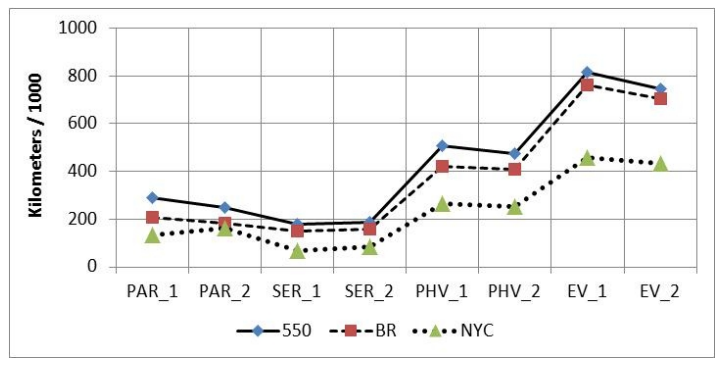

Figure 10: One battery pack life in kilometers.

Fig. 11 shows the battery pack life in years if annual operation for city bus is considered to be $80000 \mathrm{~km}$ ( $\sim 50000$ miles $)$. It was expected that at least for charge sustaining hybrids, several battery pack replacement are needed to do within the lifetime of the bus.

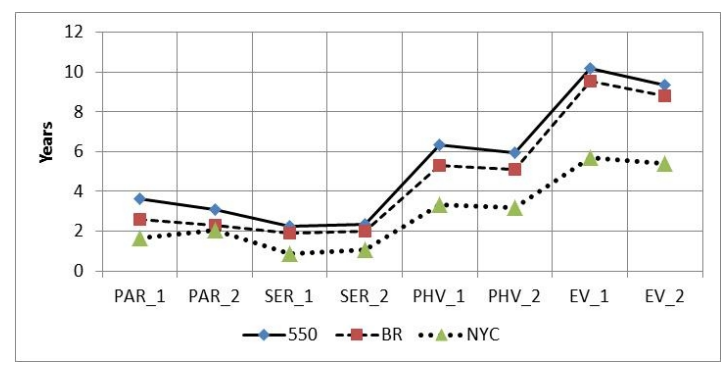

Figure 11: One battery pack life in years.

Based on these results and USABC defined battery calendar life requirements, the calendar life is less limiting requirement than the battery cycle life in city bus operation. Typical diesel city bus life in operation is around 12 years and somewhat one million kilometers [15].

\subsection{Cost}

Fig. 12-15 shows the required amount of operation kilometers of an individual bus to amortize the higher cost of the hybrid and electric city bus with three different battery cost scenarios: 1050,600 and $150 € / \mathrm{kWh}$.

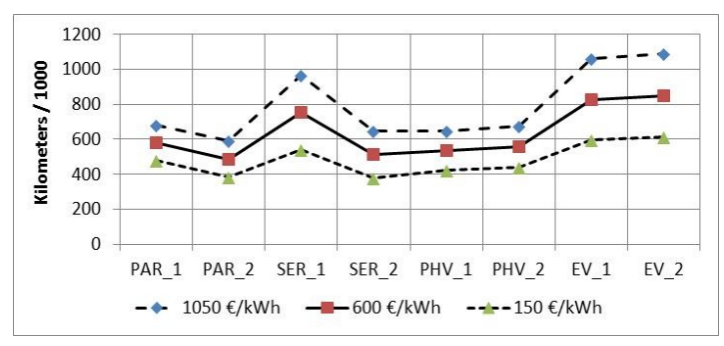

Figure 12: Payback time in cycle 550.

In most of the driving cycles, the battery cost has more impact on electric city bus payback time. There are no significant differences between charge sustaining hybrids in any driving cycle.
However, as mentioned before more powerful battery pack has an positive impact on overall performance and cost-effectiveness of the charge sustaining hybrid bus which can be observed from the results of the cases PAR_2 and SER_2.

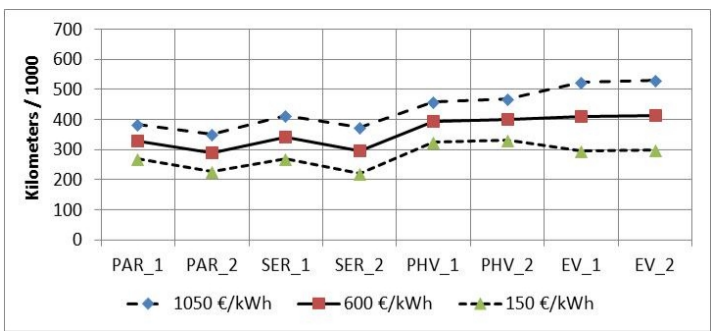

Figure 13: Payback time in cycle Braunschweig.

Even if New York Bus cycle is very low speed cycle with frequent stops, it does not favor for the plug-in hybrid and electric buses (Fig. 14). This is because the need of more buses in fleet operation has major impact on these kinds of city center driving cycles.

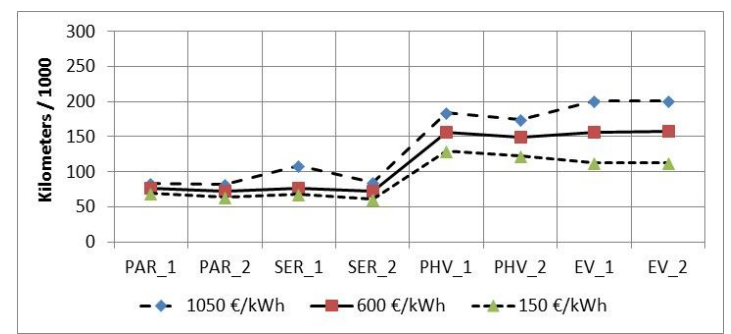

Figure 14: Payback time in cycle NYC.

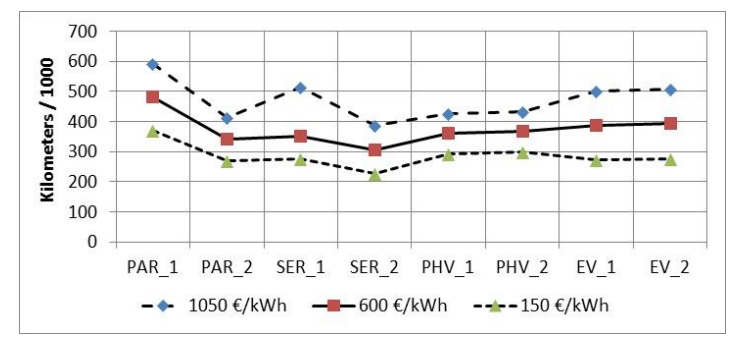

Figure 15: Payback time in cycle OCC.

The impact of initial cost of the bus on payback time in Braunschweig cycle is presented in Fig. 16.

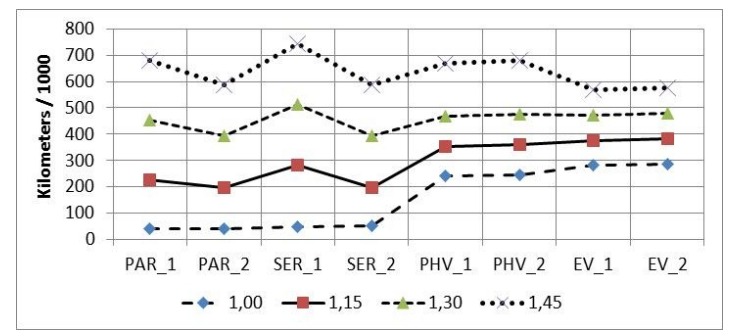

Figure 16: Initial cost impact on payback time in cycle Braunschweig. 
The initial cost consist of other cost (cost factor from 1.0 to 1.45 ) than battery and the battery cost of $600 € / \mathrm{kWh}$. According to these results, the initial costs of the hybrid or electric city bus have quite high importance to the payback time. Due to the small battery pack size of charge sustaining hybrid buses, the initial cost of the bus is clearly more impacting factor for them than the battery cost.

\subsection{Other considerations}

The battery durability and cooling requirement is strongly dependent on the battery power load cycle. The effective current of the battery gives a good reference for the power intensity. Fig. 17 presents the effective discharge current of individual battery pack in each driving cycle and bus application.

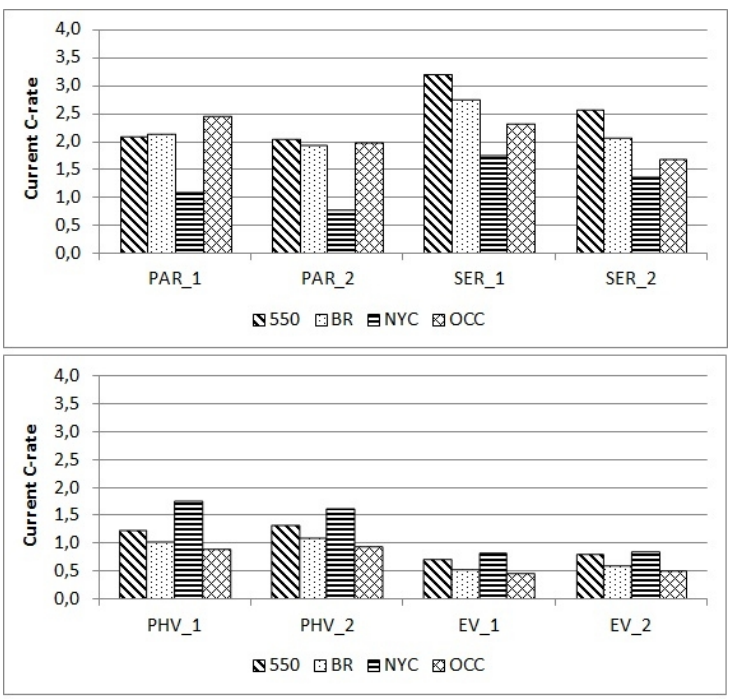

Figure 17: Battery effective discharge current.

It should be remembered here that all simulations were performed with the same control strategy. It could be advantageous for battery durability to have a dedicated battery management strategy even for each driving cycle.

\section{Conclusions}

Based on the simulation results and operation cost analysis, battery requirements for different city bus applications were evaluated. According to the evaluation, recently developed lithium-ion battery technologies offer a good performance in terms of power and energy capacity. Battery cost requirements are dependent on the driving cycle, fleet operation schedule as well as the specific bus application. Battery lifecycle requirement can be problematic in energy intensive operating cycles, because high energy throughput can shorten radically the battery life expectancy. It should be kept in mind that the battery type and chemistry choice and battery system dimensioning plays also an important role in cost effectiveness of a hybrid and electric city bus.

Based on the evaluation here, the battery overall costs, including replacements, and battery durability are practically the most important factors for hybrid and electric city buses. The latest developments in reducing the costs of lithium ion batteries have demonstrated that with high volume production, the costs can be systematically reduced. Simultaneously, increasing amount of research is being made for finding new materials, chemistries and other battery components to enhance their durability.

\section{Acknowledgments}

The author would like to acknowledge the technical support from the HybLab project which is funded by the Multidisciplinary Institute of Digitalization and Energy (MIDE) of Aalto University. The author also wishes to thank to $e B U S$ project for the financial and technical support. The eBus project is financed by the Finnish Funding Agency for Technology and Innovations (Tekes).

\section{References}

[1] M.J. Kellaway, Hybrid buses - What their batteries really need to do, Journal of Power Sources, vol. 168, no. 1, May 2007, pp. 9598.

[2] A. Burke and M. Miller, Performance Characteristics of Lithium-ion Batteries of Various Chemistries for Plug-in Hybrid Vehicles, EVS24, Stavanger, Norway, May 13 - 16, 2009.

[3] B. Scrosati and J. Garche, Lithium batteries: Status, prospects and future, Journal of Power Sources, vol. 195, no. 9, May 2010, pp. 24192430.

[4] M. Anderman, The Plug-In Hybrid and Electric Vehicle Opportunity Report, Advanced Automotive Batteries, April 2010.

[5] E. Karden, S. Ploumen, B. Fricke, T. Miller and K. Snyder, Energy storage devices for future hybrid electric vehicles, Journal of Power Sources, vol. 168, no. 1, May 2007, pp. 2-11. 
[6] M.A. Roscher, J. Assfalg and O.S. Bohlen, Detection of Utilizable Capacity Deterioration in Battery Systems, IEEE Transactions on Vehicular Technology, vol. 60, no 1, January 2011, pp. $98-103$.

[7] E. Wood, M. Alexander and T.H. Bradley, Investigation of battery end-of-life conditions for plug-in hybrid electric vehicles, Journal of Power Sources, vol. 196, no. 11, June 2011, pp. 5147-5154.

[8] D.J. Santini, K.G. Gallagher, and P.A. Nelson, Modeling of Manufacturing Costs of Lithium-Ion Batteries for HEVs, PHEVs, and EVS, EVS-25 Shenzhen, China, Nov. 59, 2010.

[9] S.M. Lukic, J. Cao, R.C. Bansal, F. Rodriguez and A. Emadi, Energy Storage Systems for Automotive Applications, IEEE Transactions on Industrial Electronics, vol. 55, no. 6, pp. 2258 - 2267, May 2008.

[10] L.T. Lam and R. Louey, Development of ultra-battery for hybrid-electric vehicle applications, Journal of Power Sources, vol. 158, no. 2, pp. 1140-1148, August 2006.

[11] T. Abe, K. Miyatake, Y. Shimoida and H. Horie, Research and Development Work on Lithium-ion Batteries for Enviromental Vehicles, World Electric Vehicle Journal, vol. 3 - ISSN 2032-6653, May 2009.

[12] V. Karvonen, Optimization and Allocation of Bus Fleet, Master's Thesis, Aalto University, 2012, Original title (Finnish): Linja-autokaluston optimointi ja kohdentaminen.

[13] A. Lajunen, Evaluation of the benefits of using dual-source energy storage in hybrid electric vehicles, IEEE Vehicle Power and Propulsion Conference, VPPC'10, Lille, France, September 2010.

[14] V.H. Johnson, Battery performance models in ADVISOR, Journal of Power Sources, vol. 110, no. 2, August 2002, pp. 321-329.

[15] N. Clark, F. Zhen, W. Wayne, and D. Lyons, Additional Transit Bus Life Cycle Cost Scenarios Based on Current and Future Fuel Prices, US DOT Federal Transit Administration, FTA-WV-267006.2008.1, July 2008.

\section{Authors}

Antti Lajunen received his M.Sc. degree in Mechanical Engineering from the Helsinki University of Technology (TKK), in 2005 and Research Master in Industrial Engineering from the Ecole Centrale Paris (ECP), in 2007. He is currently working on his doctorate research in

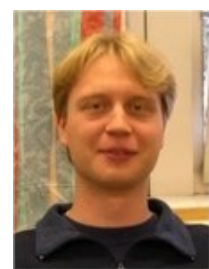
Vehicle Engineering at Aalto University, in Finland. His main research interests are hybrid vehicle modeling and simulation, energy efficiency of vehicles and work machines as well as electrochemical energy storages. 